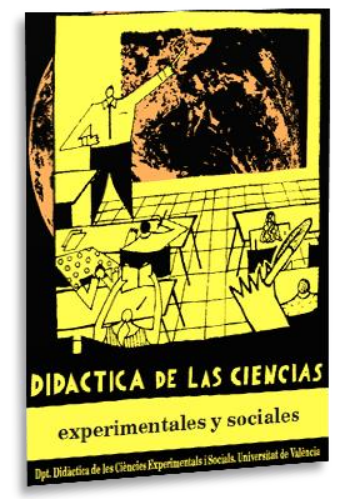

\title{
Percepción y proyección de los problemas sociales y ambientales
}

\author{
Perception and projection of social and \\ environmental problems
}

DOI: $10.7203 / D C E S .35 .12347$

\author{
Emili Puig i Vilaró \\ Universitat de Girona, epuig222@xtec.cat \\ Anna $M^{a}$ Geli de Ciurana \\ Universitat de Girona, am.geli@udg.edu \\ Xavier Besalú Costa \\ Universitat de Girona, xavier.besalu@udg.edu
}

RESUMEN: Esta investigación tiene como objetivo principal conocer la percepción y la proyección respecto a los problemas sociales y ambientales de niños en la etapa de educación primaria. Es decir, saber qué piensan actualmente los niños sobre los problemas sociales y ambientales de la Tierra y cómo ven el futuro de nuestro planeta. En la investigación se utiliza el dibujo como elemento de expresión, tanto a nivel de visión local y global como con las coordenadas temporales de presente y futuro. En los resultados de la investigación los niños manifiestan en sus dibujos una clara conciencia y un profundo sentimiento hacia las problemáticas sociales y ambientales de nuestro planeta y manifiestan su preocupación por el futuro.

Palabras Clave: percepción, proyección, sostenibilidad, social, ambiental.

ABSTRACT: This research has as main objective to know the perception and the projection regarding the social and environmental problems of children in primary education. That is, to know what children nowadays think about the social and environmental problems of the Earth and how they see the future of our planet. In the research, drawing is used as an element of expression, both at local and global vision and with the temporal coordinates of present and future. In the results of the research, children express in their drawings a clear awareness and deep feeling towards the social and environmental problems of our planet and express their concern for the future.

KEYWORDS: perception, projection, sustainability, social, environmental

Fecha de recepción: abril de 2018 Fecha de aceptación: octubre de 2018 


\section{INTRODUCCIÓN}

El objetivo de esta investigación es aproximarnos a la percepción de los problemas sociales y ambientales que tienen los niños y niñas de primaria, así como también a su proyección para un futuro a medio plazo, de 50 años.

Los dibujos, realizados por niños y niñas de las comarcas gerundenses, han servido para estudiar y evaluar su percepción de los problemas ambientales y sociales de nuestro planeta y sus perspectivas de futuro. En el estudio se recogieron un total de 482 dibujos realizados por 122 niños y niñas de edades comprendidas entre 9 y 12 años, de siete escuelas diferentes de las comarcas gerundenses.

En el estudio se ha tenido en cuenta la diversidad cultural y étnica de los participantes, buscando distintas tipologías escolares y contextos sociales diferenciados en ámbitos socioeconómicos distintos y en medios urbanos y rurales.

La técnica utilizada para manifestar sus percepciones ha sido el dibujo. Esta metodología ha permitido una aproximación indirecta al objetivo del trabajo de investigación, evitando la posible desviación de hacer las preguntas con una técnica más directa como la entrevista. Posteriormente se ha realizado una valoración cuantitativa y otra cualitativa para extraer conclusiones del estudio.

\section{EL DIBUJO COMO ELEMENTO DE INFORMACIÓN}

Para poder conocer la percepción de los problemas sociales y ambientales que tienen los niños y niñas de primaria, así como su proyección para un futuro a medio plazo, de 50 años, utilizamos una técnica de dibujo vinculada a un juego imaginario.

Las técnicas de dibujo son un camino relativamente fácil para recoger información de la percepción del presente y de la proyección del futuro social y ambiental de nuestros niños respecto a nuestro planeta (King, 1995). La utilización de dibujos con propósitos de evaluación es una herramienta poderosa, ya que es indirecta y, por tanto, para los niños y niñas no se hace evidente el objeto de estudio de la investigación. Además, la mayoría de ellos tienden a disfrutar con el juego imaginativo y el proceso de elaboración de los dibujos, sin mostrar signos de cansancio o tensión durante el desarrollo de la actividad.

Mientras que a muchos niños y niñas les desagrada responder preguntas, y las respuestas tienen una validez muy relativa, ya que pueden estar condicionadas por las preguntas, los test con dibujos pueden ser completados rápida y fácilmente y de una manera divertida, según Barraza (1999). Según Chambers (1983), los dibujos evitan barreras lingüísticas y socioculturales y posibilitan comparar entre grupos de diferentes lenguas y niveles culturales. Crook (1985) argumenta que es ampliamente reconocido que el contenido de los dibujos de los niños y las niñas puede aportar información e ideas de sus sentimientos y pensamientos sobre la situación social y ambiental del mundo. Sus dibujos abren una ventana sus pensamientos y sentimientos, sobre todo porque reflejan unas imágenes presentes en su mente.

En este estudio analizamos los dibujos de los niños y niñas como una herramienta para evaluar las percepciones sociales y ambientales de los niños de escuelas de las comarcas de Girona, y sus expectativas, preocupaciones e intereses para el futuro. Observamos los problemas sociales y ambientales que los niños representan en sus dibujos, analizando las consecuencias psicopedagógicas de estas percepciones y proyecciones. Intentamos determinar cómo los mensajes sociales y mediáticos, la cultura y la escuela tienen efecto en la formación, en los niños y niñas, de las percepciones y proyecciones sociales y ambientales sobre la crisis social y ambiental de nuestro planeta. 


\section{EL ESTUDIO DE LOS DIBUJOS DE LOS NIÑOS}

La utilización de dibujos infantiles para el estudio y análisis data del siglo XIX (Thomas y Silk, 1990). A lo largo de este período, la técnica del dibujo se ha utilizado por diferentes razones: estéticas, educativas y psicológicas.

Podemos agrupar en tres tradiciones remarcables la búsqueda de aspectos psicológicos, emocionales, sociales y educativos en los dibujos de los niños:

I. Primera: Los dibujos se analizan como proyecciones de rasgos de personalidad, interpretados siguiendo a Freud, con toda la estructura teórica psicoanalítica y sus derivaciones.

II. Segunda: Se intenta idear, validar y analizar científicamente una clasificación de indicadores emocionales para poder interpretar los dibujos de los niños. El ejemplo más identificable es el trabajo de Koppitz (1968).

III. Tercera: Consiste en que los niños representen temas importantes del entorno social y ambiental de forma personal. No se busca la evaluación de la personalidad ni una diagnosis clínica. El ejemplo más identificable es el trabajo de Laura Barraza (1999).

La utilización de la técnica del dibujo en esta investigación corresponde a la última tradición mencionada. Los dibujos de los niños se utilizan para explorar su visión de los problemas sociales y ambientales del mundo actual y su proyección en el futuro.

Los dibujos son la expresión de procesos mentales internos. Para poder comprender estos procesos y su evolución, nos podemos basar en el modelo de Luquet (1913), que propone cinco etapas de desarrollo:

1. Realismo fortuito (de 18 meses a 2 años). Los primeros garabatos demuestran conciencia de dibujo y un incremento de la coordinación entre el ojo y la mano.

2. Realismo fracasado (de 2 a 3 años). Los garabatos se vuelven más interpretables para los demás, pero los niños de esta edad aún tienen problemas para coordinar las partes de un dibujo.

3. Realismo simbólico (de 3 a 4 años). Los niños empiezan a aportar al dibujo detalles de la relación con los demás. Muchos de los dibujos parecen estar basados en simples fórmulas o esquemas.

4. Realismo intelectual (de 5 a 7 años). Los dibujos contienen elementos que los niños saben que existen, aunque no se vean normalmente. Se llaman dibujos transparencias o rayos $X$. El realismo intelectual refleja el impacto del conocimiento del dibujo.

5. Realismo visual (des de los 8 años hasta los 12). Los niños comienzan a dibujar la realidad que perciben desde un punto de vista más personal, usan proporciones y tienen en cuenta las relaciones interpersonales. Su grado de conocimiento de los fenómenos planetarios es considerable.

Esta clasificación refleja la influencia de los estadios de desarrollo cognitivo de Piaget, en los que el dibujo tiene un valor al promover y reflejar el desarrollo cognitivo. Según Piaget (1969), existe un paralelismo entre el desarrollo intelectual del niño y su dibujo. A medida que los niños se hacen mayores, sus dibujos se vuelven más detallados, mejor proporcionados y más reales.

Todo esto es importante, porque nos permitió decidir con fundamentación psicopedagógica la edad de los niños y niñas participantes en la investigación.

Por estos motivos, la edad escogida para llevar a cabo la investigación sobre la percepción y la proyección de los problemas sociales y ambientales ha sido la correspondiente al realismo visual, entre 9 y 12 años. 


\section{EL DIBUJO EN LA INVESTIGACIÓN SOCIAL Y AMBIENTAL}

El uso de dibujos de niños y niñas como una técnica con medida sistemática para evaluar sus percepciones y proyecciones respecto a los problemas sociales y ambientales se encuentra aún en proceso de desarrollo. Los dibujos de los niños se han utilizado sobre todo como indicadores emocionales para problemas específicos de carácter social o ambiental, y para determinar las actitudes que los niños tienen respecto a diferentes situaciones sociales y ambientales. Brown (1987) usó dibujos de niños de edades comprendidas entre 11 y 15 años para evidenciar el cambio de percepción en diferentes situaciones. Comparó dibujos de antes y después del desastre de Chernóbil y encontró cambios evidentes en el tiempo.

Matthews (1985) usó los dibujos de niños (entre 6 y 11 años) para representar su viaje a la escuela y el área de su casa a partir de la cartografía. Los niños eran capaces de trazar rutas complejas y de mostrar una buena apreciación de las relaciones espaciales en un área alrededor de sus casas.

Más recientemente, King (1995) usó los dibujos de niños de entre 5 y 15 años para descubrir la variedad y tipos de intereses que podían tener sobre una crisis ambiental. Les pidió que hicieran un dibujo sobre qué significaba para ellos cuando alguien decía: "Tienes que salvar el planeta". Encontró que un $87 \%$ eran conscientes de la crisis del medio ambiente. Cerca de la mitad, un $47 \%$, se representaron a sí mismos o a otros llevando a cabo acciones personales para cambios positivos, sociales y ambientales.

Finalmente, Barraza (1999), nuestra principal fuente de inspiración muestra claramente la utilización del dibujo como técnica de estudio de la percepción y proyección de los problemas ambientales. Nuestra investigación está inspirada en parte en la investigación de Laura Barraza ampliando la parte de la proyección hacia el futuro.

\section{MÉTOdO Y DESARROLLO}

Los dibujos incluidos en este estudio pertenecen a niños y niñas de quinto y sexto de primaria (de 9 a 12 años). Seleccionamos este grupo de edad porque la mente de los niños en esta etapa experimenta un importante desarrollo, tanto intelectual como socialmente, tal como expone Piaget (1969). También por la correspondencia con la etapa del realismo visual de Luquet (1913).

Estábamos interesados en descubrir si en este proceso de desarrollo los niños mostraban preocupación por los problemas sociales y ambientales. Si era así, queríamos intentar entender el grado en que la cultura, los medios de comunicación y la escuela actúan como factores influyentes en el proceso de creación de la percepción y proyección de la situación actual y futura de nuestro planeta.

\section{LOS DIBUJOS}

Para ver cómo representaban los niños sus puntos de vista sobre la situación actual y futura de nuestro planeta, a nivel global y local, se pidió a un total de 122 niños y niñas de las comarcas gerundenses que realizaran cuatro dibujos distintos, correspondientes a cada momento de observación, tal como comentaremos en el desarrollo.

En total se recogieron 482 dibujos, ya que se registraron 6 bajas durante el proceso. Los cálculos de participación fueron los siguientes: 
TABLA 1. Número de alumnos participantes

\begin{tabular}{l}
\hline $24+10+4+25+25+25+9=122$ Alumnos participantes \\
\hline $122=59$ niños +63 niñas \\
\hline $122 \times 4=488$ Total de dibujos previstos \\
\hline $488-6=482$ Total de dibujos recogidos \\
\hline
\end{tabular}

Del total de dibujos recogidos, tras un primer análisis y examen del grado de conflictos sociales y ambientales representado, se seleccionó una muestra representativa de 40 para poder llevar a cabo un análisis más operativo y profundo a nivel cualitativo. Para seleccionar esta muestra utilizamos los siguientes criterios:

I. Representatividad de los resultados globales de todo el conjunto.

II. Significatividad de los dibujos representados en la imagen.

III. Calidad y riqueza plástica de los dibujos.

IV. Relevancia de la información aportada en el dibujo. 2005.

El período de recogida de los dibujos fue durante los cursos escolares 2003-2004 y 2004-

Las escuelas participantes fueron 7. Este número vino determinado, por una parte, por nuestra disponibilidad y, por otra, por la aceptación por parte de las escuelas para participar en el estudio. Los criterios para proponer a las escuelas incluían los siguientes:

a) Escuelas de primaria que fueran mixtas

b) Voluntad de participación en el proyecto de investigación

Asimismo, se procuró buscar un equilibrio territorial entre las escuelas participantes y una representación de escuelas públicas y concertadas, y también entre escuelas del Programa Escuelas Verdes y otras. Todo ello se plasmaba en buscar el equilibrio entre estos tres ejes:

a) Escuelas del Programa Escuelas Verdes y otras escuelas

b) Escuelas urbanas y rurales

c) Escuelas públicas y escuelas concertadas

Aplicando los criterios mencionados, las siete escuelas participantes, con el número de alumnos, fueron:

TABLA 2. Las escuelas participantes

\begin{tabular}{clc}
\hline $\mathbf{N .}^{\mathbf{0}}$ & NOMBRE DE LA ESCUELA & $\mathbf{N}^{\mathbf{0}}$ ALUMNOS \\
\hline $\mathbf{1}$ & CEIP Sant Gregori & 24 \\
\hline $\mathbf{2}$ & CEIP Font de la Pólvora & 10 \\
\hline $\mathbf{3}$ & CEIP Boadella d'Empordà & 4 \\
\hline $\mathbf{4}$ & CEIP Malagrida (Olot) & 25 \\
\hline $\mathbf{5}$ & Escola Dr. Masmitjà (Escuela Verde) & 25 \\
\hline $\mathbf{6}$ & Escola La Salle Cassà & 25 \\
\hline $\mathbf{7}$ & Escola Sagrada Família & 9 \\
\hline
\end{tabular}


Por tanto, las escuelas participantes en este estudio no responden solo a centros que han estado involucrados activamente en proyectos medioambientales.

El nivel social y económico de los niños participantes en el estudio varía. Algunas de las diferencias sociales y económicas se tienen en consideración, si bien su evaluación no es el principal propósito de este estudio.

El estudio completo consta de cuatro situaciones o momentos espacio-temporales de observación. Estas cuatro situaciones corresponden al eje espacio-tiempo. Concretamente, en el espacio observamos la dimensión global y la dimensión local, y en la dimensión temporal observamos el presente o actualidad y el futuro, con una perspectiva de 50 años. Para las cuatro situaciones de observación se propone a los niños y niñas una situación diferente. Las dos primeras se refieren a la percepción actual, global y local, y los dos últimos a la proyección, global y local, en un futuro a 50 años. Es importante destacar que tanto para la percepción actual como para la proyección de futuro se han contemplado la visión global y la visión local. Estas cuatro situaciones espacio-temporales de observación se resumen en el siguiente esquema:

FIGURA 1. Espacio y tiempo de los problemas sociales y ambientales

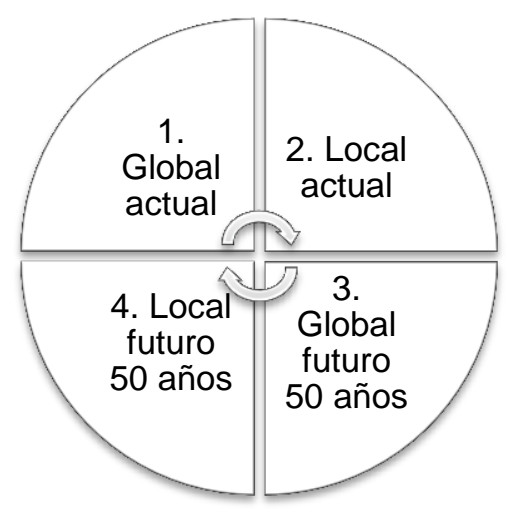

De forma resumida y esquemática, los cuatro dibujos, correspondientes a las cuatro situaciones o momentos de observación, son:

FIGURA 2. Percepción y proyección de los problemas sociales y ambientales

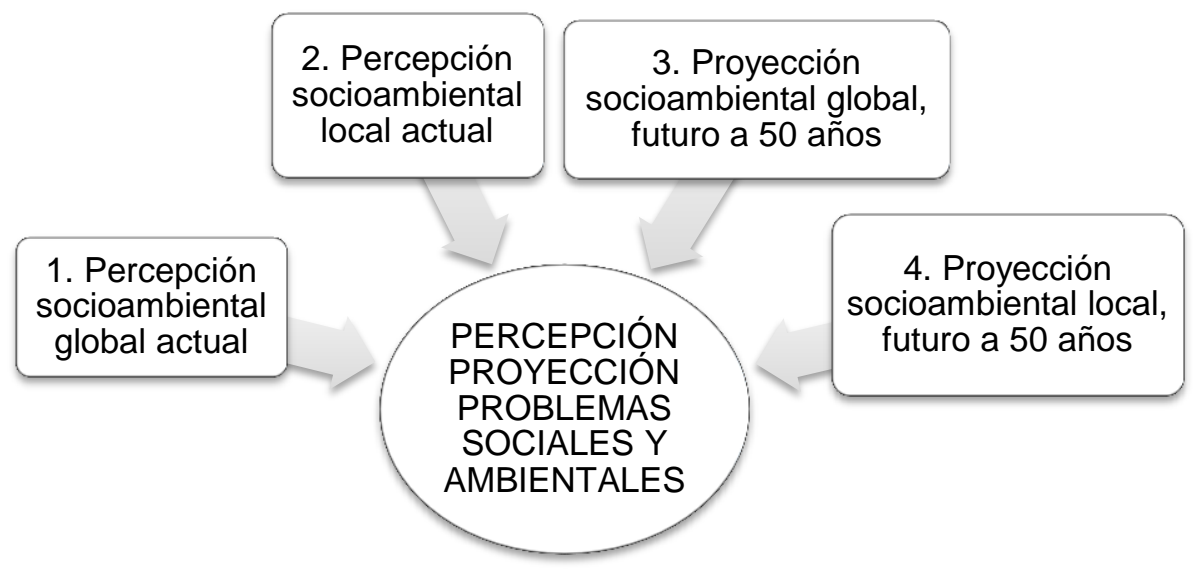

1. Percepción socioambiental global actual:

Pretende captar la percepción de los problemas sociales y ambientales con una dimensión perceptiva global y en el momento temporal actual.

2. Percepción socioambiental local actual: 
Pretende captar la percepción de los problemas sociales y ambientales con una dimensión perceptiva local y en el momento temporal actual.

3. Proyección socioambiental global en el futuro, a 50 años:

Pretende captar la proyección de futuro de los problemas sociales y ambientales con una dimensión perceptiva global y en un momento futuro, a 50 años.

4. Proyección socioambiental local en el futuro, a 50 años:

Pretende captar la proyección de futuro de los problemas sociales y ambientales con una dimensión perceptiva local y en un momento futuro, a 50 años.

Los dibujos se realizaron en cuatro sesiones de unos 50 minutos aproximadamente. Algunas las realizó el investigador y otras, el maestro tutor del curso. A fin de evitar diferencias, no se dio ninguna explicación antes de la sesión, solo se leyeron las instrucciones del enunciado para introducir la actividad tal como se expone en la Figura 3.

FIGURA 3. Los cuatro textos que acompañaban la petición de los 4 dibujos representativos de la percepción y proyección socioambiental, local y global, actual y en el futuro a 50 años.

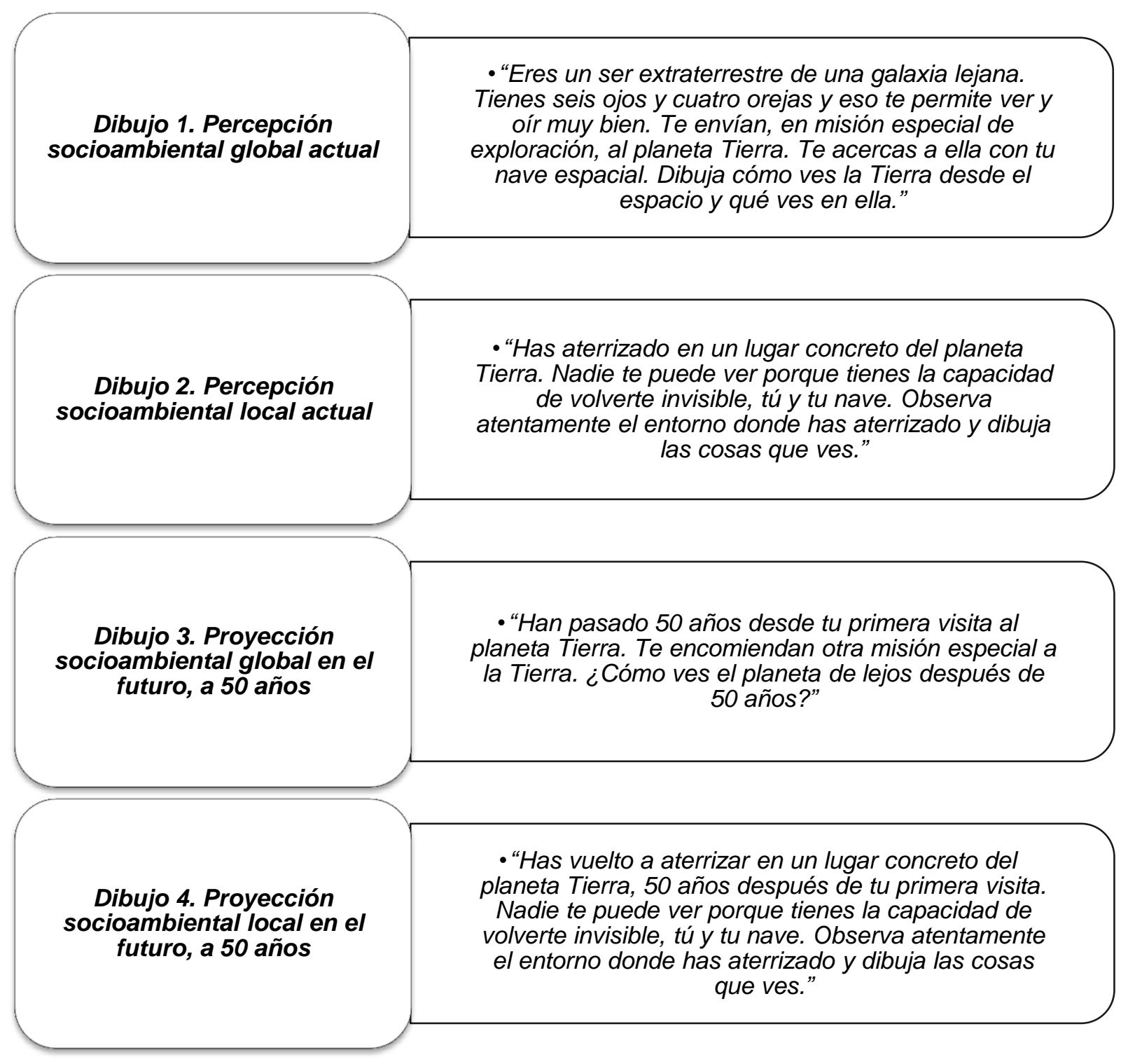


Para asegurar que lo que dibujaran los niños y niñas sería interpretable claramente, sin ambigüedades, se completaba la información extraída del dibujo con una pequeña entrevista que se realizaba en el momento de la entrega de los dibujos. El guion era el siguiente:

a) ¿Qué has dibujado? (descripción)

b) ¿Qué representa? (representación simbólica)

c) ¿Qué piensas sobre los dibujos? (pensamiento)

d) ¿Qué sientes sobre el dibujo? (sentimientos y emociones)

e) Aclaraciones de partes del dibujo no fácilmente identificables.

f) Otras observaciones particulares del niño o niña.

La consigna de la actividad era que se imaginasen que eran seres extraterrestres enviados desde un planeta de una galaxia lejana en misión especial al planeta Tierra para determinar y describir cómo eran las cosas aquí. Se les pidió que hicieran cuatro dibujos, en un período de cuatro a seis semanas, basados en los cuatro enunciados recogidos en la figura 3.

La primera propuesta introdujo y situó a los niños y niñas en la actividad. Sirvió para evaluar sus percepciones sobre el presente. Además, esta cuestión daba información sobre qué sabían respecto al planeta Tierra, sus continentes y océanos, y sobre la habilidad y conocimiento de los niños y niñas para dibujar y representar el mapa del mundo.

La segunda propuesta dio evidencias de los lugares por los que los niños y niñas estaban más interesados o preocupados, en el momento presente.

Las propuestas tercera y cuarta se utilizaron para evaluar las proyecciones de los niños y niñas y sus expectativas y preocupaciones sobre el futuro, en un plazo de 50 años. Estas cuestiones perseguían básicamente constatar si eran capaces de representar sus proyecciones de futuro sobre algunos de los problemas ambientales y sociales del mundo a partir de sus percepciones actuales.

La idea de proponer un plazo de proyección al futuro, a 50 años, se debe a que se consideró un período de tiempo suficientemente amplio para poder observar cambios significativos, y adecuado al concepto de sostenibilidad. Habitualmente, tanto a nivel educativo como económico y político, estamos acostumbrados a planificar en períodos de tiempo mucho más cortos, de cuatro o máximo ocho años. Pero la sostenibilidad y la educación para la sostenibilidad deben contemplar el futuro con unas perspectivas más amplias, de más años, huyendo de la inmediatez del corto plazo; en definitiva, pensando en las generaciones futuras.

\section{ANÁLISIS DE LA INFORMACIÓN}

Tras una primera observación de los 482 dibujos y tras las primeras y sorprendentes impresiones, construimos los instrumentos de observación de los dibujos adecuadas a cada una de las cuatro situaciones o momentos de observación. A fin de elaborar y validar los instrumentos de observación utilizamos las técnicas de triangulación.

La triangulación es una estrategia de investigación muy utilizada en ciencias sociales. El uso de técnicas de triangulación de los resultados obtenidos durante el trabajo de campo goza de una gran valoración en la bibliografía de métodos de investigación social y educativa (Morse y Chung, 2003).

Una gran parte de los científicos sociales consideran que cuanto mayor sea la variedad de las metodologías, datos e investigadores utilizados en el análisis de unos datos específicos mayor será la fiabilidad de los resultados finales. Así, la utilización simultánea de métodos cualitativos y cuantitativos permite ofrecer una visión más global y equilibrada (Olsen, 2004).

Desde esta perspectiva, hay que considerar que la triangulación es, por encima de todo, un proceso de ampliación y verificación de los resultados. En su desarrollo se trata de identificar y corregir las limitaciones metodológicas y los sesgos de los datos y de los investigadores. No es, por 
tanto, un mero puente entre los métodos cuantitativos y cualitativos, sino un principio inspirador de la investigación orientado invariablemente hacia el progreso científico (Oppermann, 2000).

Procedimos, pues, a presentar los dibujos recogidos y las propuestas de pautas de observación, análisis e interpretación de los dibujos sobre la percepción y la proyección de los problemas sociales y ambientales de la Tierra a diferentes profesionales, con el fin de recoger sus aportaciones y mejorar los instrumentos de observación. Se presentó a maestros de primaria, profesores de secundaria, profesores universitarios, pedagogos y psicopedagogos y especialistas de las ciencias sociales y ambientales.

Finalmente, una vez recogidas las aportaciones, sugerencias y mejoras de todos los profesionales mencionados, consideramos adecuadas las pautas de observación, análisis e interpretación de los dibujos de los niños y niñas sobre su percepción y proyección de los problemas sociales y ambientales.

\section{Pautas de ObServación}

Todos los dibujos están identificados con una etiqueta donde se recoge la información de sus datos básicos:

FiguRA 4. Datos básicos de los dibujos

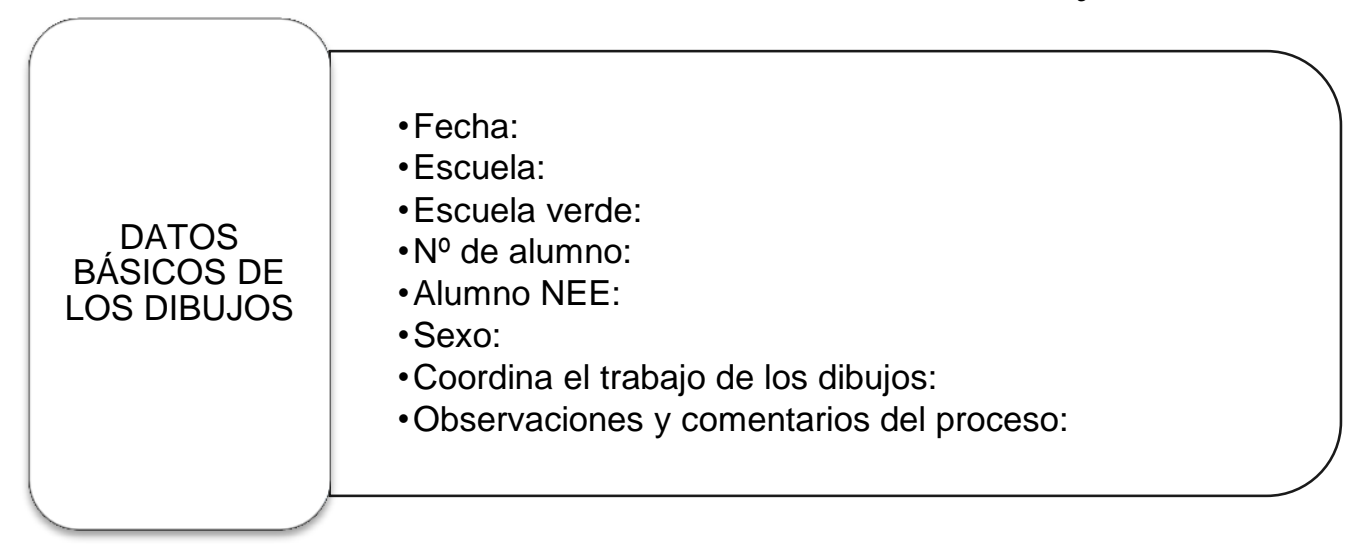

Para la observación sistemática de los dibujos del grupo 1, sobre la percepción socioambiental global actual, se utilizó la siguiente pauta de observación:

FiguRA 5. Pauta de observación sistemática de los dibujos del grupo 1

OBSERVACIÓN SISTEMÁTICA, DIBUJOS DEL GRUPO 1

-Continentes:

- Océanos:

- Países:

- Colores utilizados:

- Armonía:

- Conflictos sociales:

-Conflictos ambientales:

- Otras valoraciones:

- VALORACIÓN: 
Para la observación sistemática de los dibujos del grupo 2, sobre la percepción socioambiental local actual, se utilizó la siguiente pauta de observación:

FIGURA 6. Pauta de observación sistemática de los dibujos del grupo 2

\section{OBSERVACIÓN SISTEMÁTICA, DIBUJOS DEL GRUPO 2}

- Lugar de aterrizaje:

- Situación observada:

- País o lugar geográfico:

- Colores utilizados:

-Armonía:

- Conflictos sociales:

- Conflictos ambientales:

- Otras observaciones:

-VALORACIÓN:

Para la observación sistemática de los dibujos del grupo 3, sobre la proyección socioambiental global en un futuro a 50 años, se utilizó esta pauta de observación, con las siguientes categorías:

FiguRA 7. Pauta de observación sistemática de los dibujos del grupo 3.

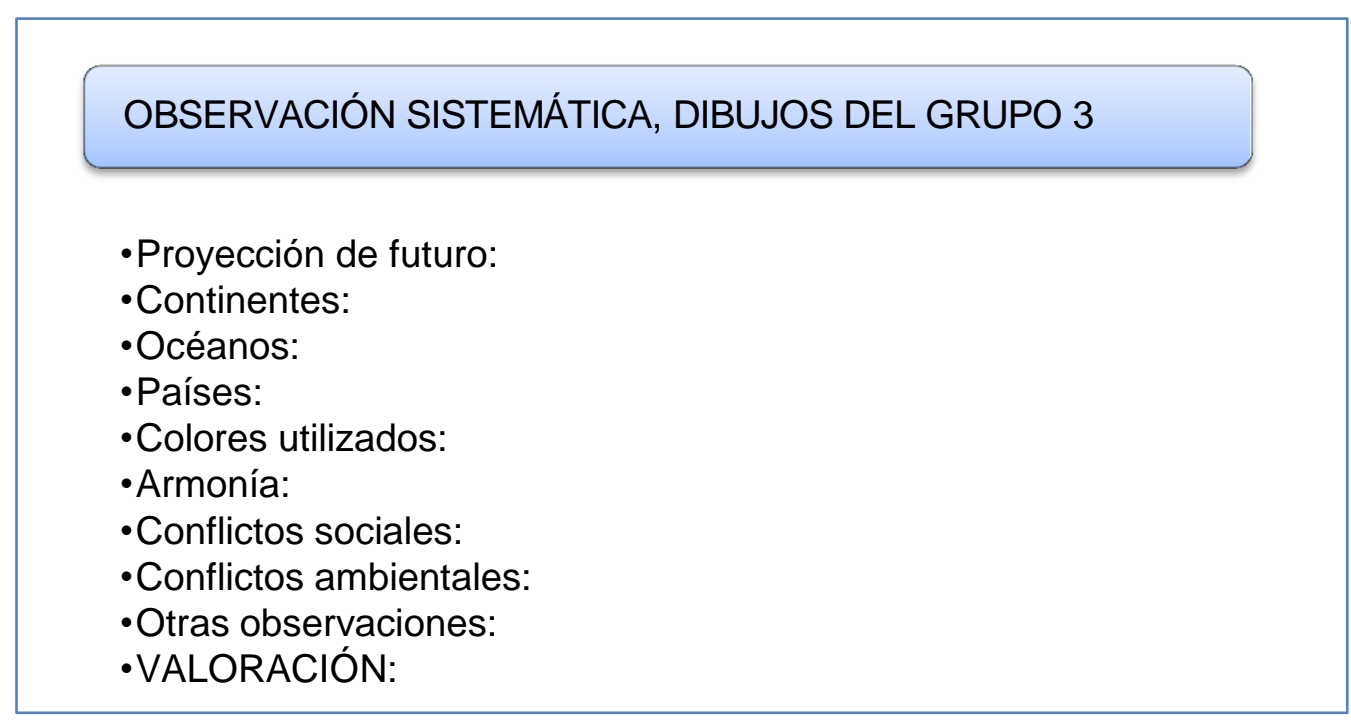

Para la observación sistemática de los dibujos del grupo 4, sobre la proyección socioambiental local en un futuro a 50 años, se utilizó esta pauta de observación, con las siguientes categorías: 
FIGURA 8. Pauta de observación sistemática de los dibujos del grupo 4.

OBSERVACIÓN SISTEMÁTICA, DIBUJOS DEL GRUPO 4

-Proyección de futuro:

- Lugar de aterrizaje:

- Situación observada:

- País o lugar geográfico:

- Colores utilizados:

-Armonía:

- Conflictos sociales:

- Conflictos ambientales:

- Otras observaciones:

-VALORACIÓN:

\section{CRiterios de ANÁLiSiS}

Establecimos criterios orientativos de análisis y observación para cada uno de los cuatro dibujos realizados. Los dibujos relativos a cada pregunta fueron analizados por separado utilizando la pauta sistematizada de observación y los criterios de análisis y observación del contenido.

A continuación, se enumeran los criterios de análisis y observación utilizados en cada uno de los cuatro dibujos:

1. Percepción socioambiental global actual:

- Formas indefinidas para representar la tierra y el agua.

- Formas reconocibles para representar países.

- Países indefinidos incluyendo alguno o todos los elementos (agua, animales, plantas, casas y personas).

- Dibujos irreconocibles o incompletos.

- Problemas del mundo actual que los niños perciben.

- Colores cálidos o fríos más utilizados.

- Trazo suave o duro.

- Grado de armonía o conflicto general del dibujo.

2. Percepción socioambiental local actual:

- Todo parece armónico o se aprecia ausencia de conflicto.

- Representación de un problema ambiental.

- Representación de un problema social.

- Problema no determinado.

- Lugares y situaciones no identificables.

- Lugares y situaciones identificables.

- Lugares que los niños prefieren dibujar.

- Problemas del mundo actual que los niños perciben.

- Colores cálidos o fríos más utilizados.

- Trazo suave o duro.

- Grado de armonía o conflicto general del dibujo.

3. Proyección socioambiental global en el futuro, a 50 años:

- Cosas mejoradas. 
- Cosas que van a peor.

- Hay cambio, pero no está claro si es mejor o peor.

- No hay ningún cambio.

- Irreconocible o incompleto.

- Problemas que los niños proyectan en el futuro.

- Colores cálidos o fríos más utilizados.

- Trazo suave o duro.

- Grado de armonía o conflicto general del dibujo.

4. Proyección socioambiental local en el futuro, a 50 años:

- Cosas mejoradas.

- Cosas que van a peor.

- Hay cambio, pero no está claro si es mejor o peor.

- No hay ningún cambio.

- Irreconocible o incompleto.

- Problemas que los niños proyectan en el futuro.

- Lugares que los niños prefieren dibujar.

- Colores cálidos o fríos más utilizados.

- Trazo suave o duro.

- Grado de armonía o conflicto general del dibujo.

En términos de fiabilidad y validez, y debido al desarrollo de este método para evaluar la representación de los problemas sociales y ambientales, fue preciso revisar los criterios para analizar la información dos veces.

Con todos estos criterios se realizó una cuidadosa observación y análisis de cada dibujo, lo que permitió determinar, finalmente, su categorización como armonía o conflicto, tanto desde los parámetros sociales como desde los parámetros ambientales.

Para la interpretación y análisis de los dibujos se contó con la colaboración de profesionales especialistas en desarrollo cognitivo de los niños y niñas y de profesionales de la educación que también habían contribuido a generar las pautas de observación de los dibujos.

\section{ANÁLISIS E INTERPRETACIÓN DE LOS DIBUJOS}

Seguidamente presentamos el análisis e interpretación de tres dibujos para cada una de las cuatro situaciones o momentos de observación:

FigURA 9. Análisis y observación de los dibujos

\begin{tabular}{|c|c|c|}
\hline \multicolumn{2}{|c|}{$\begin{array}{l}\text { ANÁLISIS E INTERPRETACIÓN DE LOS DIBUJOS SOBRE } \\
\text { LA PERCEPCIÓN Y LA PROYECCIÓN DE LOS } \\
\text { PROBLEMAS SOCIALES Y AMBIENTALES DE LA TIERRA }\end{array}$} & \\
\hline & Dibujo 1. Percepción socioambiental global actual & \\
\hline & Dibujo 2. Percepción socioambiental local actual & \\
\hline & Dibujo 3. Proyección socioambiental global en el fu & turo, a 50 años \\
\hline & Dibujo 4. Proyección socioambiental local en el f & ro, a 50 años \\
\hline
\end{tabular}




\section{DIBUJO 1.1}

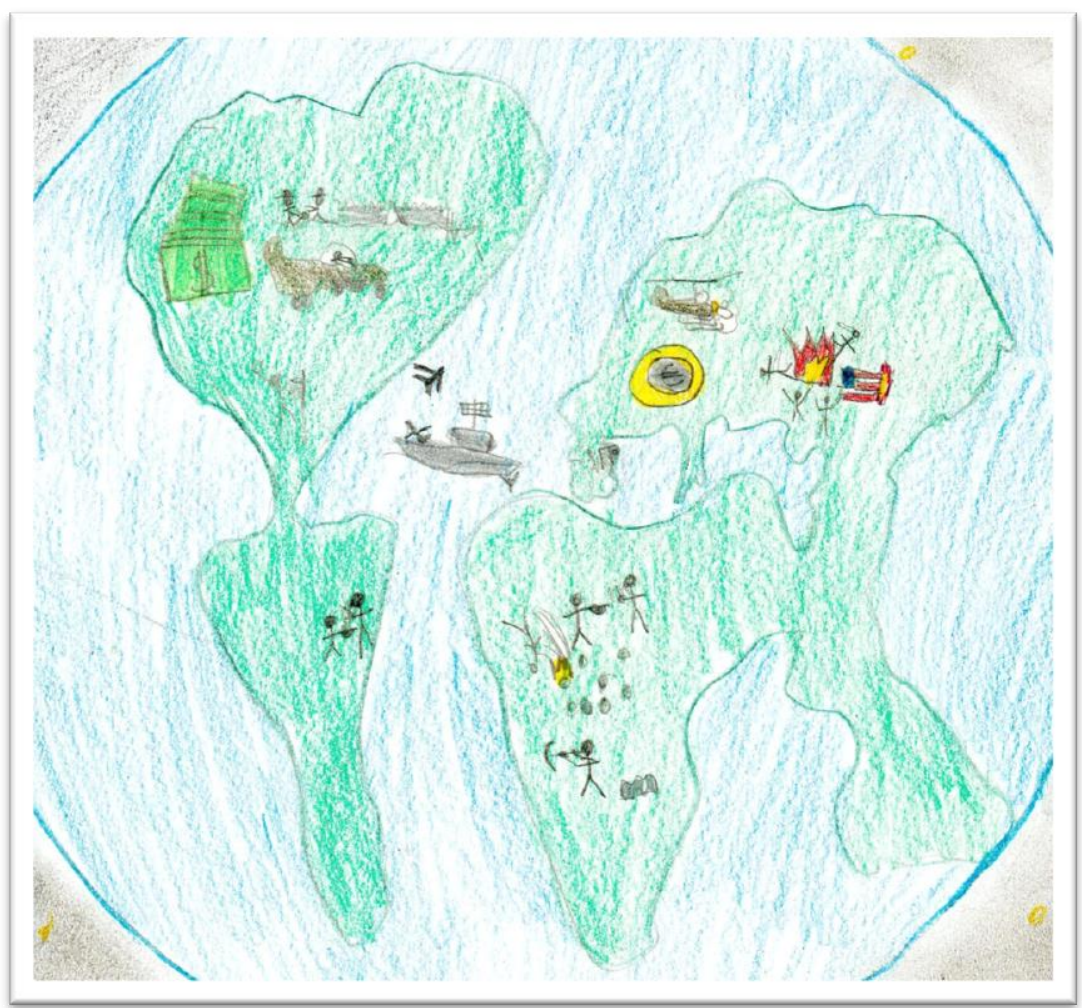

El dibujo 1.1 muestra conflictos sociales en forma de guerras. Representa también diferencias claras entre el Norte y el Sur a nivel económico y en la utilización de recursos tecnológicos: helicópteros y submarinos en el Norte $\mathrm{y}$ arcos y piedras en el Sur. No aparece, ni en los continentes ni en los océanos, ningún tipo de expresión o símbolo de biodiversidad vegetal $\mathrm{o}$ animal.

\section{DIBUJO 1.3}

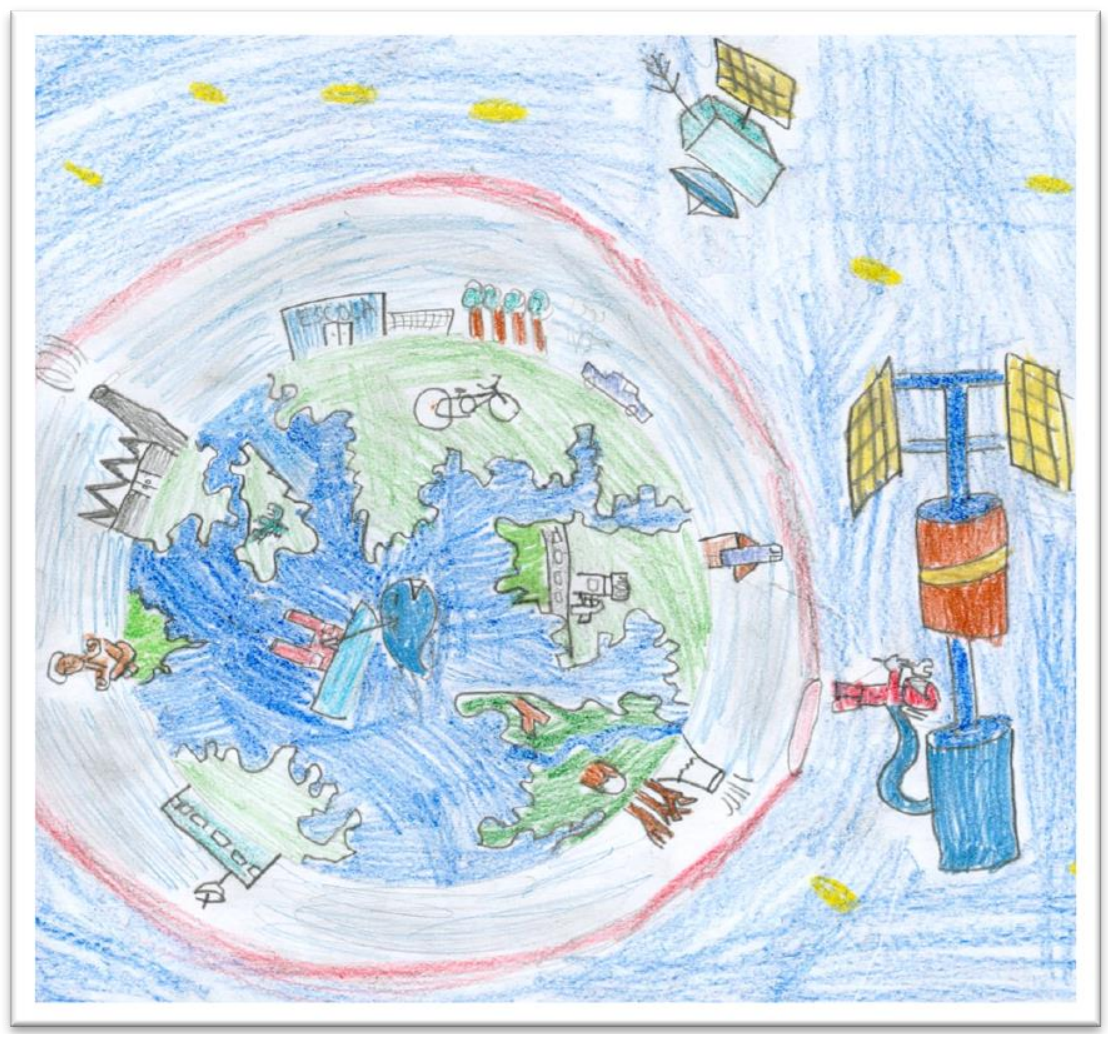

El dibujo 1.3 muestra de manera clara dos conflictos ambientales, como la contaminación por parte de las fábricas y la caza de ballenas.

Existe también armonía en elementos sociales como la escuela, los árboles, el hombre que medita y el hombre que arregla la estación espacial. 


\section{DIBUJO 2.2}

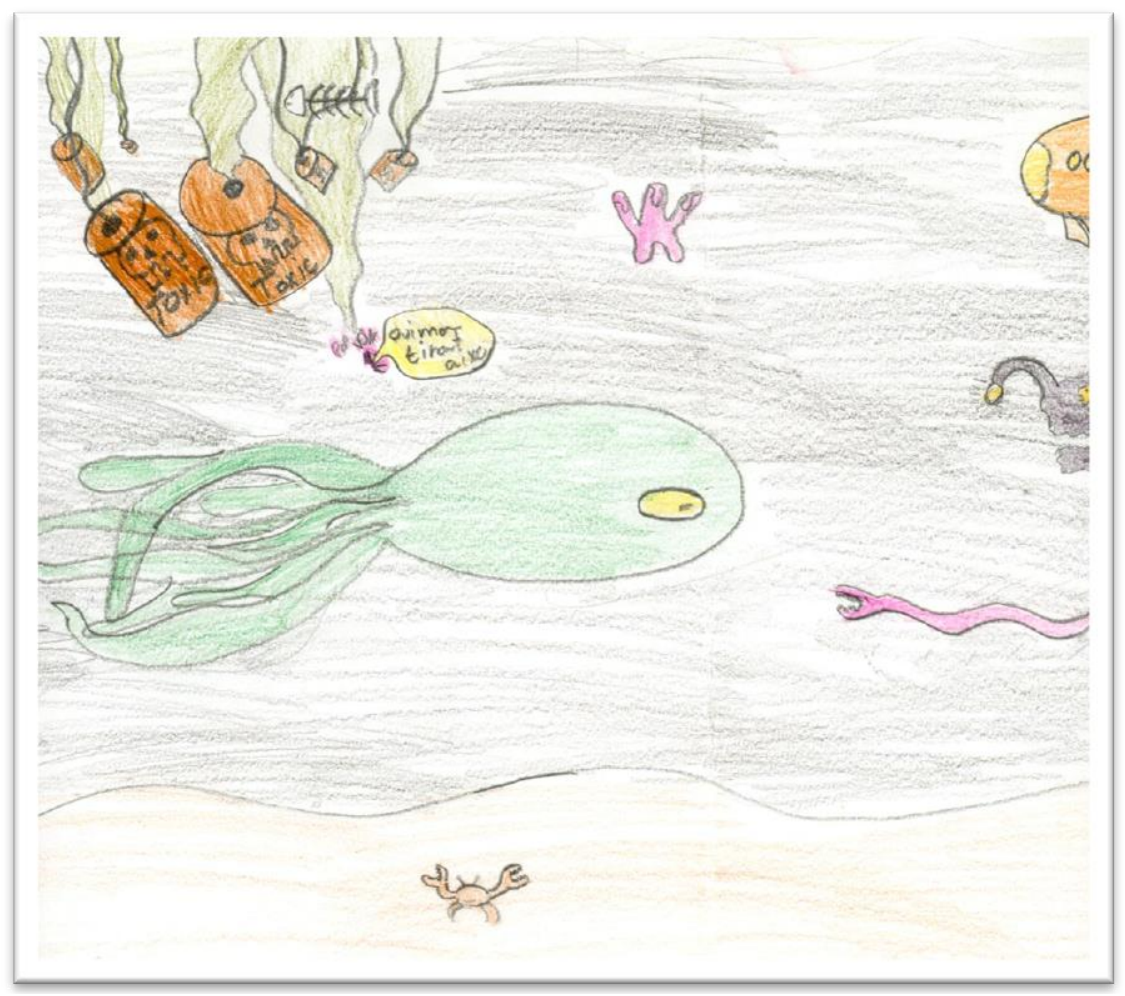

El dibujo 2.2 muestra una de las consecuencias negativas de la sociedad industrializada, como es la contaminación del mar con sustancias tóxicas que traen la muerte a su paso, como se puede observar por el líquido verde que derraman y en el pez muerto que aparece en la estela de los bidones de sustancias tóxicas.

\section{DIBUJO 2.4}

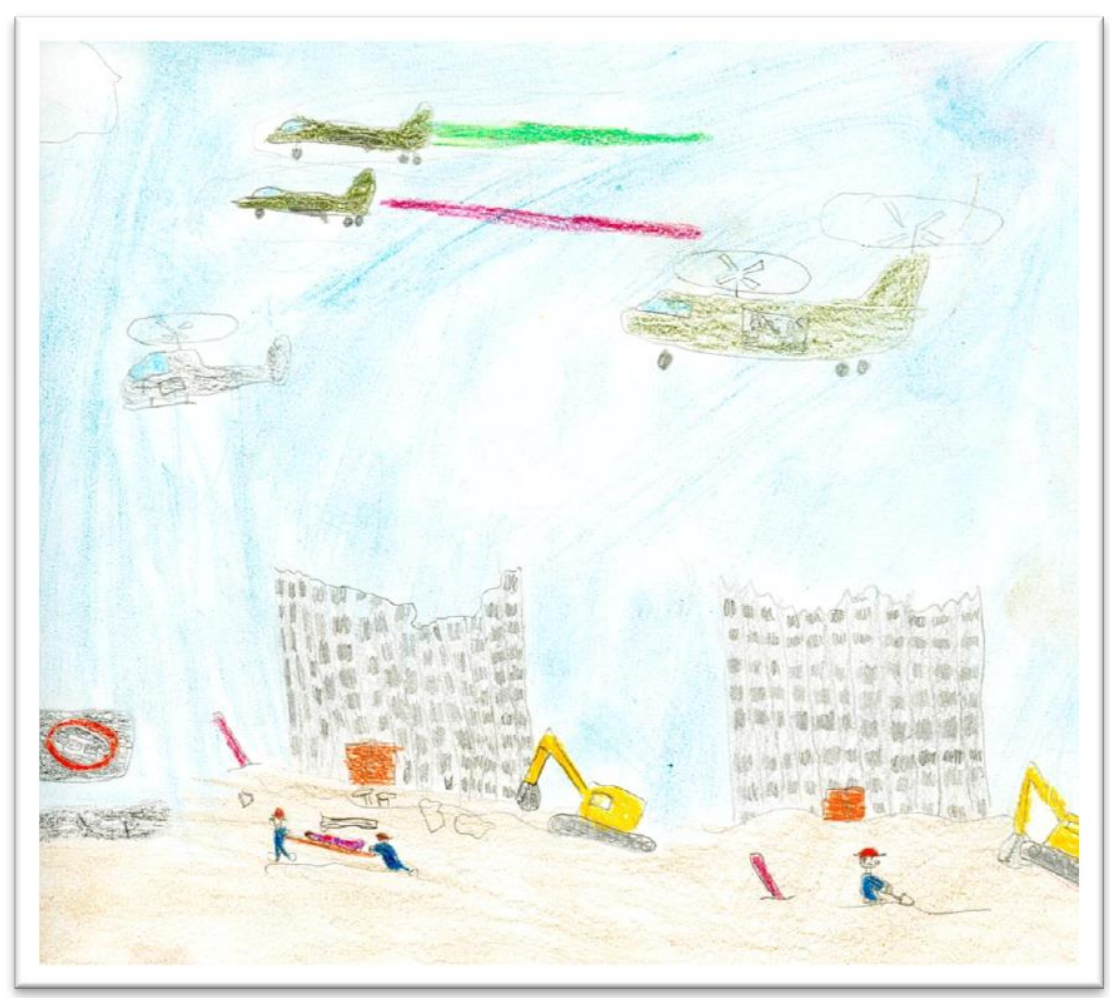

El dibujo 2.4 muestra la fase posterior a una guerra. En concreto, se muestra a unos sanitarios trasladando a una persona herida $\mathrm{y}$ unos operarios que están trabajando en la reconstrucción de los edificios, ayudados por varias máquinas. En el cielo se ven dos aviones y dos helicópteros, uno de ellos de guerra. 


\section{DIBUJO 3.1}

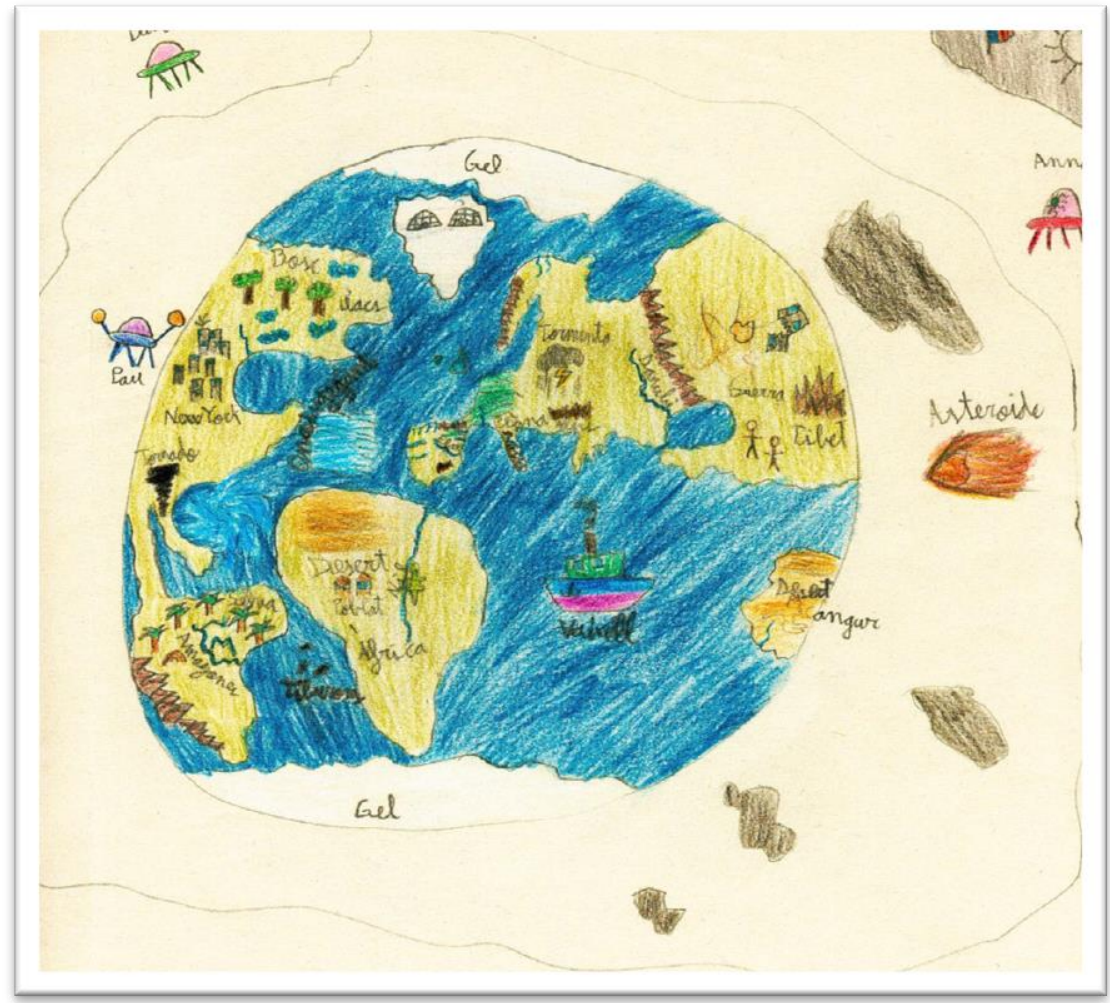

\section{DIBUJO 3.9}

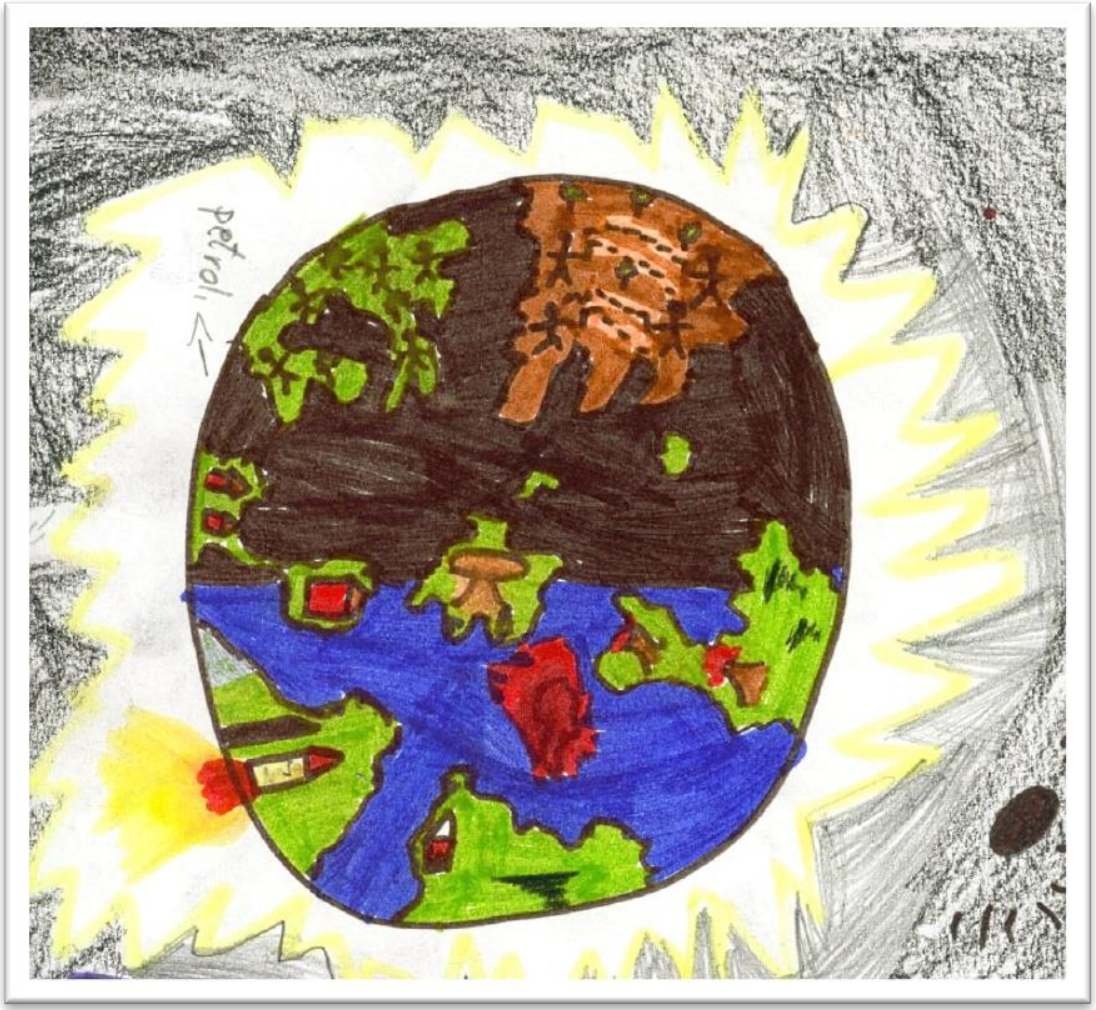

El dibujo 3.1 muestra un mundo muy parecido al actual, con la diferencia de las naves espaciales.

Se representan guerras, el conflicto en el Tíbet, fenómenos naturales, biodiversidad animal y vegetal.

También es posible observar importantes diferencias entre el Norte y el Sur.

El dibujo 3.9 muestra un mundo dominado por la guerra, la contaminación, las catástrofes naturales y los meteoritos.

El estudiante se ayuda mucho de los colores para expresar esta negatividad, agresividad y falta de confianza en el futuro. 


\section{DIBUJO 4.2}

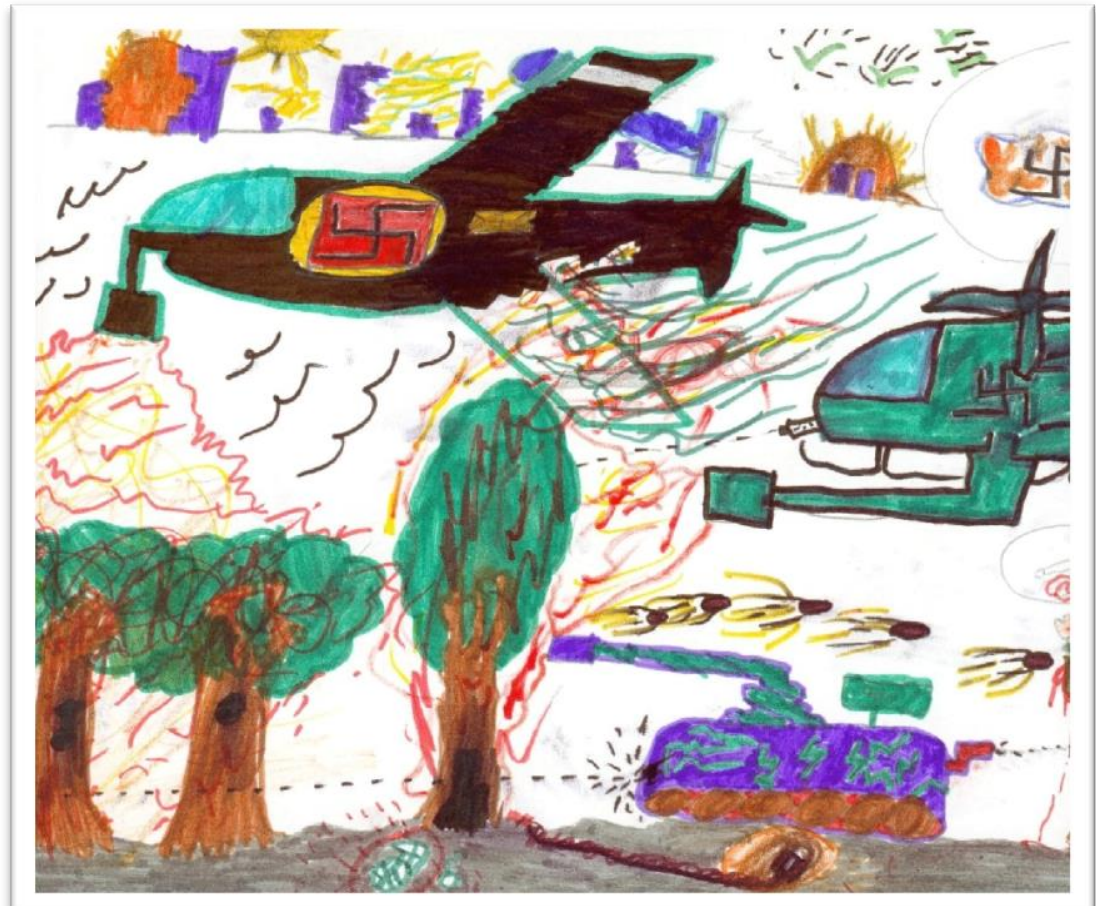

El dibujo 4.2 muestra una dura escena de guerra que recuerda a la II Guerra Mundial, debido a la simbología utilizada. Describe cómo esta situación puede acabar no siendo tan solo un conflicto social, sino también ambiental al dibujar los árboles ardiendo.

\section{DIBUJO 4.5}

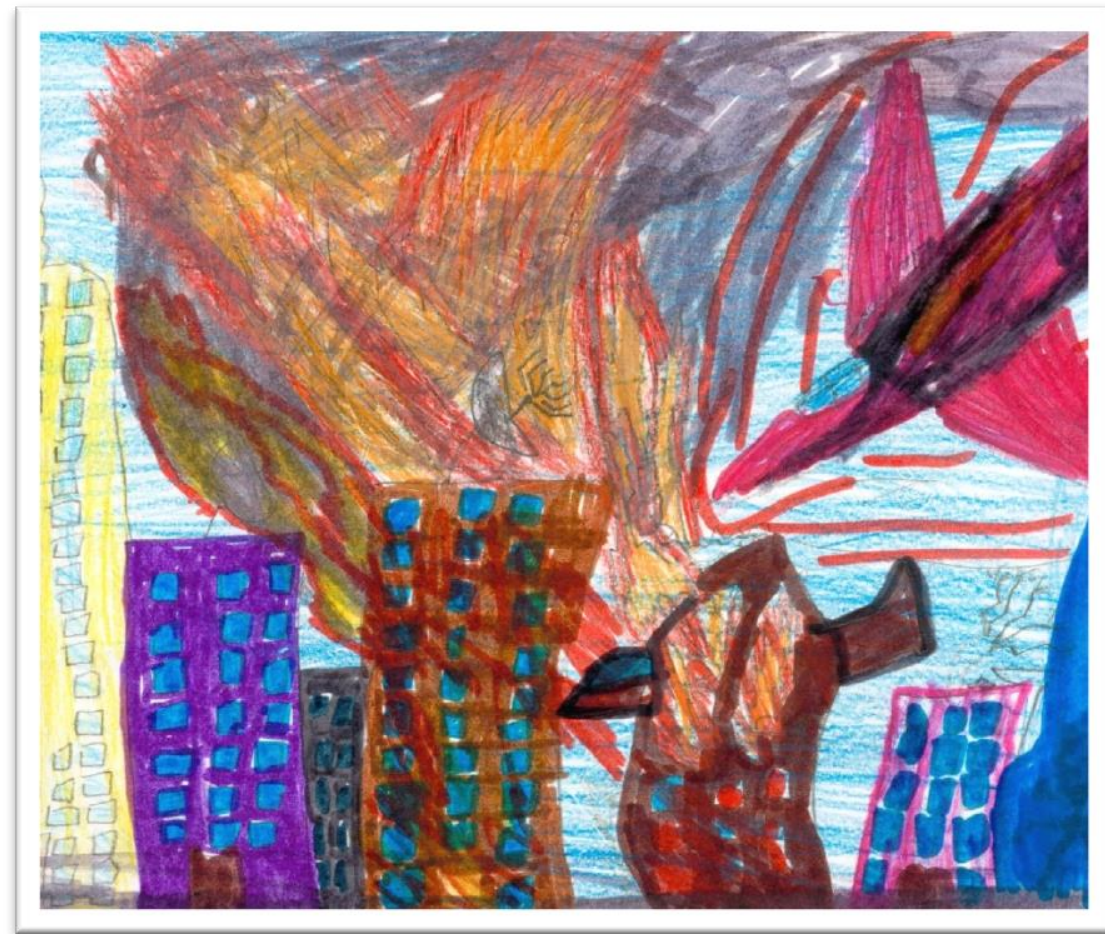

El dibujo 4.5 muestra una situación que nos es familiar: dos aviones estrellándose contra unos rascacielos. Se interpreta que en el futuro seguirán sucediendo situaciones violentas de terrorismo y guerra como las vividas hasta ahora. Principalmente expresa problemática social. 


\section{DESCRIPCIÓN DE LOS RESULTADOS}

Los resultados relativos a la percepción socioambiental global actual muestran que casi el $90 \%$ de los niños y niñas perciben el planeta Tierra como un objeto redondo, con formas definidas para representar los continentes y los océanos. La mayoría $(60 \%)$ fueron capaces de dibujar territorios muy bien definidos, con formas muy detalladas de diferentes países y continentes. Solo un 3\% de los dibujos representaba al planeta solo con agua y tierra, sin formas definidas. Un $95 \%$ incluyeron otros elementos en los dibujos (animales, árboles, personas, construcciones, vehículos...). Muy pocos dibujos (2\%) representaban al planeta como los dibujos animados (el mundo tenía una cara triste, aguantaba muchos edificios y estaba contaminado). El resto (98\%) lo representaron tal como corresponde a la etapa del realismo visual, es decir, dibujando la realidad que perciben desde un punto de vista más personal, utilizando proporciones y teniendo en cuenta las relaciones interpersonales. Una muy pequeña parte de la muestra $(<1 \%)$ eran dibujos irreconocibles y solo uno de los niños no dibujó nada. El $70 \%$ de los niños y el $60 \%$ de las niñas representaron como mínimo un problema social o ambiental en sus dibujos relacionados con la percepción socioambiental global actual.

GRÁFICO 1. Resultados relativos a la percepción socioambiental global actual

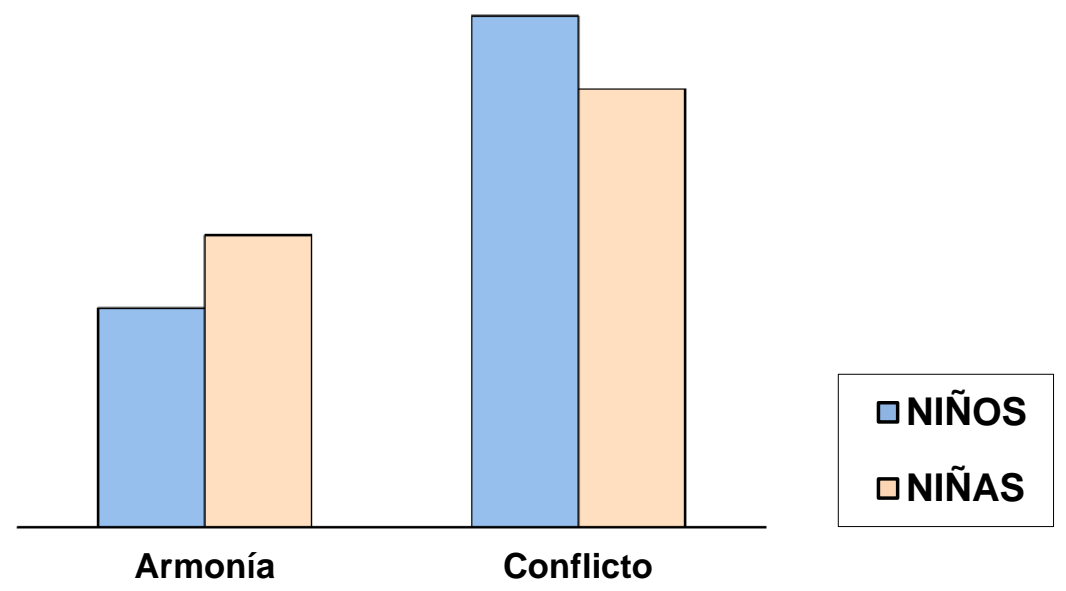

Los resultados relativos a la percepción socioambiental local actual muestran que cerca de un $30 \%$ de los niños y un $55 \%$ de las niñas no representaron ningún problema en sus dibujos, que mostraban entornos locales en armonía con el medio ambiente y en el aspecto social. Todo parece correcto: las flores, los árboles, el agua, el sol, los animales y la gente comparten el medio. No obstante, el $70 \%$ de los niños y el $45 \%$ de las niñas representaron como mínimo un problema social o ambiental en sus dibujos. Problemas como la contaminación y la destrucción, cosas que no funcionan, guerra, violencia, desechos, deforestación, especies en extinción, calentamiento global, desastres naturales... Un $25 \%$ dibujaron lugares concretos, incluyendo supermercados, aeropuertos, fábricas de chocolate, parques temáticos, cines o playas, pero sin dar suficiente información para determinar si percibían en ellos algún tipo de problema.

Solo un $7 \%$ de los dibujos mostraban lugares y situaciones irreconocibles. Cabe destacar diferencias muy significativas entre los niños y las niñas. El resultado de nuestro estudio revela una diferencia del $25 \%$ en representaciones conflictivas por parte de los niños respecto a las niñas. 
GRÁFICO 2. Resultados relativos a la percepción socioambiental local actual

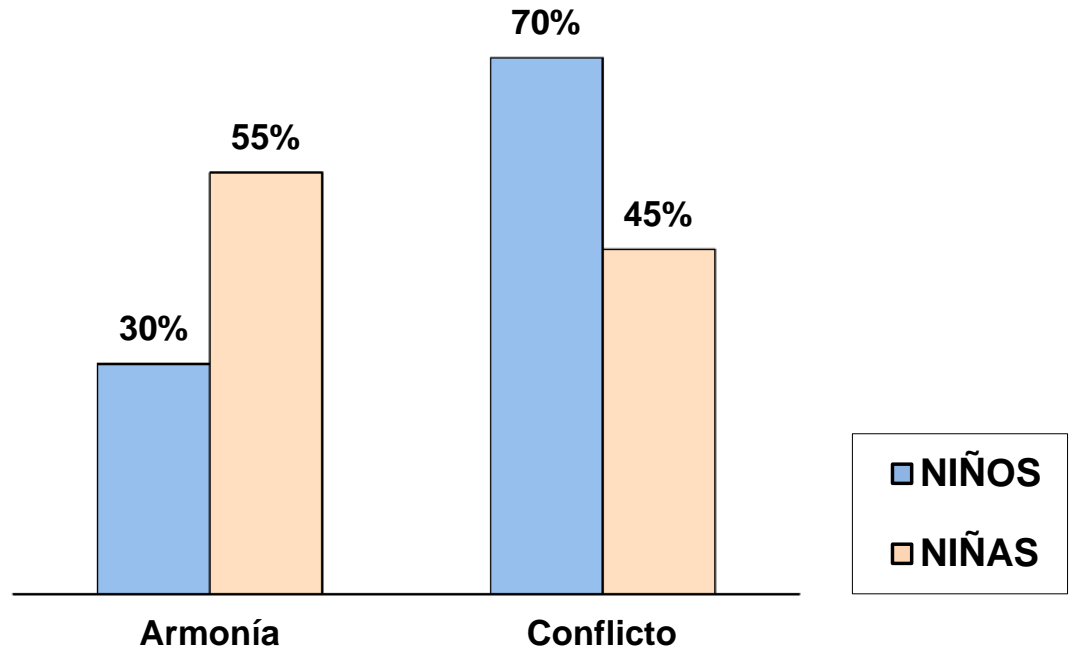

Los resultados relativos a la proyección socioambiental global en el futuro, a 50 años, muestran que las expectativas de niños y niñas no son demasiado optimistas. El $80 \%$ de los niños y el $60 \%$ de las niñas prevén que el mundo, globalmente, estará peor dentro de 50 años. Los dibujos muestran una profunda preocupación por problemas globales como la contaminación, la guerra, el calentamiento del planeta, la extinción de especies, la lluvia ácida, los desechos, la deforestación y la falta de agua, entre otros. Como consecuencia de todo ello, expresaban en sus comentarios a la pregunta del significado de los dibujos que el mundo sufriría muchos problemas: los continentes se dividirían, el sol explotaría, los meteoritos destruirían la Tierra, los terremotos destruirían el mundo, habría grandes inundaciones, los marcianos conquistarían la Tierra, el mundo estaría superpoblado y todo sería destruido.

Para el $20 \%$ de los niños y el $40 \%$ de las niñas existía aún alguna esperanza para el futuro. Sus dibujos revelaban que las cosas mejorarían, que la tecnología ayudaría en este proceso, que existiría un sistema de limpieza para la contaminación del aire y del agua, y que las guerras desaparecerían y se viviría en armonía.

Un $10 \%$ y de manera especial niños expresó algún cambio incierto de cara al futuro, sin especificar si se trataba de cambios positivos o negativos. Por ejemplo, la transformación de pueblos en grandes ciudades. Solo un $2 \%$ de los dibujos no mostraban cambios.

En general, la visión de niños y niñas respecto al futuro era más pesimista que optimista. Sin embargo, existe una diferencia del $20 \%$, muy significativa, entre la visión de conflicto y la de armonía en el futuro. 
GRÁFICO 3. Resultados relativos a la proyección socioambiental global en el futuro, a 50 años

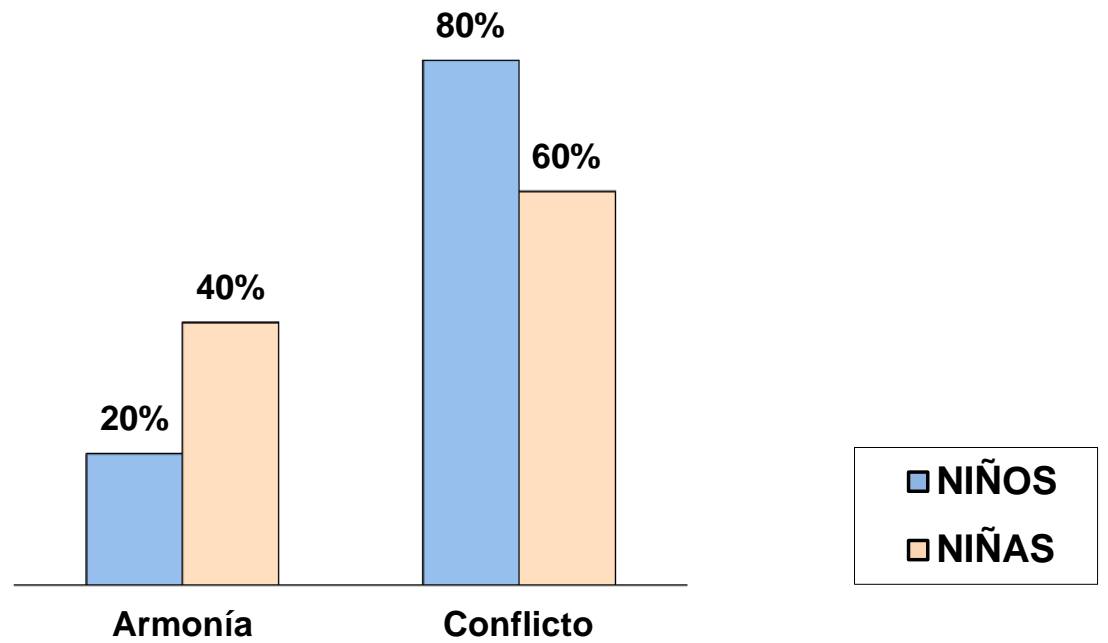

Finalmente, en cuanto a la proyección socioambiental local en el futuro, a 50 años, los resultados muestran que el $85 \%$ de los niños y el $60 \%$ de las niñas prevén que el mundo estará peor dentro de 50 años a nivel local. Los dibujos muestran una profunda preocupación por problemas locales como la contaminación, la guerra, la extinción de especies, la lluvia ácida, los desechos, la deforestación y la falta de agua, entre otros. Como consecuencia, expresaban en sus comentarios preocupación por el futuro en general y algunos por su futuro personal. El $15 \%$ de los niños y el $40 \%$ de las niñas aún tienen alguna esperanza en el futuro. Sus dibujos revelaban que las cosas mejorarían, que la tecnología ayudaría en este proceso, que existiría un sistema de limpieza para la contaminación del aire y del agua, y que las guerras desaparecerían y se viviría en armonía. En general, la visión de los niños y niñas respecto al futuro es mucho más pesimista que optimista. Sin embargo, existe una diferencia del $25 \%$ entre niños y niñas, muy significativa, sobre la visión de conflicto y la visión de armonía, en el futuro a nivel local, ya que un $85 \%$ de los niños y un $60 \%$ de las niñas pensaban que las cosas serían peores en el futuro, a nivel local. No se ven diferencias significativas en la visión local entre escuelas especialmente sensibilizadas hacia el medio y el resto de escuelas.

GRÁFICO 4. Resultados relativos a la proyección socioambiental local en el futuro, a 50 años

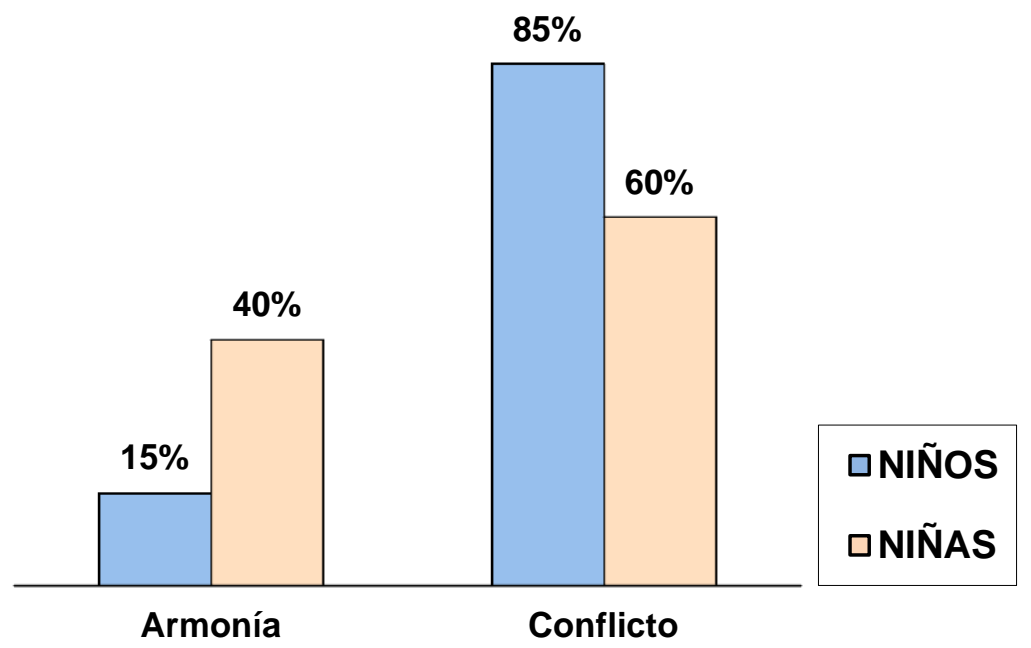




\section{DISCUSIÓN Y VALORACIÓN DE CONCLUSIONES}

Todo lo que percibimos está influenciado por la percepción de otras personas o por los medios de comunicación, es decir, por el contexto educativo, social y cultural. Un ejemplo de ello lo hallamos en el resultado de cómo los niños y niñas representaron la visión de la Tierra desde el espacio: casi el $95 \%$ de los niños tenían conocimientos previos de cómo es esta visión. La gran mayoría eran capaces de dibujar formas definidas para representar los continentes y los océanos, y muchos dibujaron países y continentes reconocibles. Los niños y niñas mostraban, además de su habilidad para dibujar, su conocimiento y su percepción visual. Estos elementos son vitales para el desarrollo del pensamiento y de las representaciones mentales.

Los dibujos estaban influidos también por los conocimientos previos, la edad y la habilidad al dibujar. En este caso, la edad de los niños y el desarrollo cognitivo eran factores importantes para tener en cuenta. Casi todos los niños participantes en el estudio se encontraban en la misma etapa de desarrollo del dibujo, el realismo visual, según la clasificación de Luquet (1913).

Los resultados de este estudio muestran que los niños y niñas de diferentes contextos sociales, culturales y económicos no presentan diferencias significativas en sus percepciones y proyecciones de los problemas sociales y ambientales. En sus dibujos se manifestaban más similitudes que diferencias. El esquema de algunos dibujos era muy similar y algunos representaban lo mismo. No se perciben diferencias significativas entre escuelas especialmente sensibilizadas hacia el medio y el resto de escuelas.

También cabe mencionar que se halló simbolismo local y familiaridad en los dibujos de los niños y niñas. Los dibujos son una parte común del día a día: por tanto, los niños los utilizan para recrear cosas que les son familiares.

En este estudio se utilizó un procedimiento abierto y neutro para ver si los niños y niñas estaban preocupados o no por los problemas sociales y ambientales. Los resultados revelan que, aunque la técnica se diseñó para ser neutra y para evitar inclinaciones o influencias en el contenido de los dibujos, los niños y niñas mostraron una profunda preocupación por los problemas sociales y ambientales, tal como se refleja en sus dibujos.

En otras investigaciones similares (King, 1995), una posible explicación del porqué los niños eran tan conscientes de la crisis ambiental es que el procedimiento no haya sido acertado. Se decía a los niños lo que debían hacer, y se les explicaba que el mundo necesitaba ayuda. Los niños sabían desde el principio lo que debían dibujar, y mostraban una fuerte inclinación a representar problemas ambientales concretos. Frases como "Tienes que salvar el planeta" o parecidas tienen connotaciones ambientales claras y todo el mundo lo relaciona con: reciclar, no tirar desechos, salvar especies en peligro de extinción, salvar los bosques... Son frases que han sido utilizadas en todo del mundo. Políticos, gobiernos, grupos ecologistas y otras instituciones y entidades suelen utilizar las en su propio interés. En este estudio se hizo un esfuerzo consciente y calculado para evitar esta situación.

En ninguna de las cuatro situaciones a dibujar se mencionó nada que comportase observar problemas sociales o ambientales. Solo se invitaba a la exploración y a la observación libre. Cuando se pidió realizar los dibujos 3 y 4, un $30 \%$ de las niñas y un $40 \%$ de los niños representaron aún más problemas que en los dibujos 1 y 2. Muchos de estos problemas eran de tipo ambiental (contaminación, deforestación, fugas nucleares...) y otros eran de carácter social (guerras, conflictos, diferencias Norte-Sur). La contaminación del aire figura como uno de los más representados, simbolizado con fábricas, tubos de escape de los coches y emisiones radiactivas. Esto demuestra cómo está afectando a la vida de los niños la crisis ambiental. También corrobora la teoría de que los niños y niñas también dibujan lo que ven y oyen.

Es preciso plantearse la pregunta de si los niños y niñas escolarizados en centros del Programa Escuelas Verdes, especialmente sensibilizadas respecto al medio ambiente, son más conscientes de los problemas ambientales y sociales. Los resultados del estudio muestran que no existen diferencias significativas en los niveles de preocupación por dichos problemas entre los 
alumnos de Escuelas Verdes y los del resto de escuelas. Esta constatación induce a pensar que la percepción y la proyección de los problemas sociales y ambientales estarían más relacionadas con la influencia del mensaje social y mediático sobre la crisis social y ambiental de nuestro planeta que con las diferencias de programas escolares.

Según nuestra investigación, no parece que los alumnos del programa de escuelas verdes estén más preocupados que los demás. De todos modos, en un estudio sobre el conocimiento y comprensión de conceptos ecológicos por parte de los niños (Barranza, 1996), la autora halló que cuando pedía a los niños que identificaran su fuente de información ambiental, la escuela jugaba un papel mucho más importante.

De forma resumida, quisiéramos sintetizar otras conclusiones importantes y significativas del estudio:

- El uso de dibujos de niños y niñas como técnica sistemática para evaluar las percepciones y proyecciones respecto a los problemas sociales y ambientales se demuestra como una técnica eficaz, neutra y que no genera influencia del investigador en los investigados. Sin embargo, aún se encuentra en proceso de estudio y valoración.

- Los dibujos que aparecen en este estudio responden al mensaje social y mediático sobre la crisis social y ambiental de nuestro planeta.

- Niños y niñas de edades comprendidas entre 9 y 12 años manifiestan en sus dibujos una clara conciencia y un profundo sentimiento respecto a los problemas sociales y ambientales.

- Solo un $20 \%$ de los niños y niñas participantes no tienen o no expresan una conciencia clara sobre los problemas sociales y ambientales.

- Los niños y niñas manifiestan preocupación por el futuro. Algunos tienen miedo respecto a la incertidumbre del futuro, otros expresan una visión pesimista.

- Muy pocos niños y niñas tienen una visión optimista del futuro, menos de un $20 \%$.

- Los problemas sociales y ambientales que más les preocupan son los conflictos bélicos, la contaminación ambiental, los residuos, la pérdida de biodiversidad y el calentamiento de la Tierra. Los problemas de tipo ambiental más dibujados han sido: contaminación, deforestación, fugas nucleares, residuos, pérdida de biodiversidad y calentamiento de la Tierra. Y los de carácter social: guerras, conflictos, hambre, pobreza, diferencias Norte-Sur...

- En los dibujos 3 y 4, un $30 \%$ de las niñas y un $40 \%$ de los niños representaron más problemas aún que en los dibujos 1 y 2.

- Los niños y niñas de las escuelas del Programa Escuelas Verdes, que supuestamente estarían más sensibilizados respecto a los problemas que afectan al medio ambiente, no muestran más preocupación ni social ni ambiental que los del resto de escuelas.

- No se hallan diferencias significativas en los niveles de preocupación entre los alumnos de escuelas urbanas y los de escuelas rurales.

- Creemos que la percepción de los problemas sociales y ambientales que se manifiesta en los dibujos recogidos responde a la realidad que vivimos. Es muy preocupante que en las proyecciones de futuro predominen los escenarios de conflicto, tanto a nivel social como ambiental.

- Les datos del estudio, que reflejan una preocupante percepción y una alarmante proyección de los problemas sociales y ambientales, nos obligan y empujan, como educadores, a definir, delimitar e impulsar la educación para la sostenibilidad construyendo modelos psicopedagógicos que la faciliten. 


\section{Referencias}

Barraza, L. (1996). Environmental Knowledge and Attitudes of English and Mexican School Children (Tesis Doctoral). University of Cambridge.

Brown, J.M., Henderson, J. y Armstrong, M.P. (1987). Children's perceptions of nuclear power stations as revealed through their drawings. Environmental Psychology, 7, 189-199.

Chambers, D.W. (1983). Stereotypic images of the scientist: the draw-a-scientist test. Science Education, 67, 255-265.

Crook, C. (1985). Knowledge and appearance. En N.H. Freeman y M. V. Cox (Eds.), Visual Order: the nature and development of pictorial representation. Cambridge: Cambridge University Press.

Cuervo López, L., García Gómez, J. y García Ferrandis, I. (2015). Cambio de percepción de los niños de preescolar sobre su ambiente, mediante una intervención educativa con enfoque local. Revista Bio-grafía. Escritos de la Biología y su enseñanza, número extraord. De 2015, 1731-1746. DOI: 10.17227/20271034.vol.0num.0bio-grafia1731.1746

Hugckle, J. (1996). Education for Sustainability. Londres: Earthscan.

King, L.D. (1995). Doing their Share to Save the Planet. Children and Environmental Crisis. New Jersey: Rutgers University Press.

Koppitz, E. (1968). Psychological Evaluation of Children's Human Figure Drawings. Londres: Grune \& Stratton.

Luquet, G.H. (1913). Les dessins d'un enfant: étude psychologique. París: Félix Alcan.

Matthews, M.H. (1985). Young children's representations of the environment: a comparison of techniques. Environmental Psychology, 5, 261-278.

Morse, J. M. y Chung, S.E. (2003). Toward Holism: The Significance of Methodological Pluralism. International Journal of Qualitative Methods, 2(3), 13-20.

Olsen, W. (2004) Triangulation in Social Research: Qualitative and Quantitative Methods Can Really be Mixed. En M. Holborn, Development in Sociology (pp. 103-118). Causeway Press.

Opperman, M. (2000). Triangulation. A Methodological Discussion. International Journal of Tourism Research, 2(2), 141-146.

Puig, E. (2016) Educar per a la sostenibilitat. Percepció i projecció de les problemàtiques socials $i$ ambientals. Per un model psicopedagògic d'educació per a la sostenibilitat (Tesis Doctoral). Universitat de Girona. Recuperado de http://hdl.handle.net/10803/403346

Thomas, G. y Silk, A. (1990). An Introduction to the Psychology of Children's Drawings. Londres: Harvester Wheatsheaf.

Vidal, M. (1997). Enfocaments, mètodes i àmbits de la investigación psicopedagògica. Barcelona: Universitat Oberta de Catalunya.

\section{Cómo CITAR ESTE ARTÍ́CULO}

Puig i Vilaró, E., Geli de Ciurana, A. M. y Besalú Costa, X. (2018). Percepción y proyección de los problemas sociales y ambientales. Didáctica de las ciencias experimentales y sociales, 35, 91-112. DOI: 10.7203/DCES.35.12347 